\title{
Conservation Level Assessment - Application to a heritage building
}

\author{
Fernanda Rodrigues ${ }^{1,{ }^{*}, \text { Raquel Matot }}{ }^{2}$, Anibal Costa ${ }^{1}$, Alice Tavares ${ }^{1}$, Jorge Fonseca ${ }^{2}$, \\ and Ana Alves ${ }^{2}$ \\ ${ }^{1}$ RISCO, Civil Engineering Department, Univeristy of Aveiro, 3810-193 Aveiro, Portugal \\ ${ }^{2}$ Civil Engineering Department, Univeristy of Aveiro, 3810-193 Aveiro, Portugal
}

\begin{abstract}
An evaluation methodology to estimate the envelope's degradation level (DL) was developed being after object of adjustment and improvement. The methodology is based on visual survey and in the application of the Failure Mode and Effects Analysis (FMEA) method allied to evaluation scales, aiming to achieve building condition assessment and prioritizing refurbishment interventions. In Portugal, the high buildings number needing refurbishment justified the evolution and improvement of the original methodology of state of conservation assessment of residential buildings at controlled costs. This methodology firstly developed and applied for residential buildings was based on an evaluation scale of eight levels, which was after adjusted to five levels. This simplification aims an easier application of this methodology and provides users with a clear understanding of his features. A summarised evolution of this methodology will be depicted in this paper and will be applied to a heritage building located in the city of Oporto, in Portugal. Beyond the evolution of this buildings conservation assessment methodology, this paper aims to show its usefulness for heritage buildings condition assessment, through the application to a case study.
\end{abstract}

\section{Introduction}

Buildings degradation is an inevitable and progressive process being the deterioration a natural path that occurs during the time due to the interaction of several factors [1]. Portuguese national statistics depict the high number of building in bad conservation state, indicating that there are more than 1 million buildings requiring refurbishment actions [2]. Therefore, it is essential to suggest adequate proposals based on a suitable methodology of building condition assessment for Portuguese buildings stock.

Several Building Condition Assessment methodologies have been developed. Most of their scales are of four or five evaluation degrees. Some are developed to give the conservation level, evaluating the level of building repair needs based on a visual survey, such as [3] and the Portuguese method for buildings condition assessment developed by LNEC under the 2006 revision of the urban rental system [4, 5]. This method allows evaluating the condition of the building for renting throughout visual inspections carried

*Corresponding author: mfrodrigues@ua.pt 
out by qualified technicians. There are other European methods for building condition assessment as: the English method of Housing Health and Safety Rating System (HHSRS) [6], the French method to assess the condition of buildings that may be declared inhabitable [7], the Dutch standard NEN 2767-1, NEN2767-2 and NEN 2767-3 [8, 9, 10], the EPIQR (Energy Performance Indoor Environmental Quality Retrofit) [11], and TOBUS (Tool for Selecting Office Building Upgrading Solutions), which were developed within European research $[12,13]$.

Other scales for assessing the building envelopes faults were found, and they are based on different criteria: on the extension of the damage, like [14], or combining damage extension and frequencies, such as [15] or combining severity and extension, as [16-20]. However, in these methods is not evident the causes of the detected faults. Thus, a methodology to evaluate building degradation was developed by [1] that aims to define the building degradation level. The methodology is named "State of conservation assessment of residential buildings at controlled costs" - SCARBCC. Throughout the building envelope inspections and the data collected from users interviews, this method allows to achieve the building degradation level [21] and to define the building degradation state that is the goal of the methodology. The degradation level (DL) reflects the anomalies severity, both in terms of extension and in terms of gravity, being possible to establish intervention priorities in the building stock. Given the complexity of the application of [1] methodology, it was modified, being the eight-level scale modified to a five-level one [22] that will be applied.

This paper presents a case study located in Oporto, in the north of mainland Portugal, in which the methodology of building condition assessment developed by $[1,21,23]$ and the adjustments made by [22] was applied. The main purpose is to validate the application of this last version of the methodology for any type of buildings, regardless of its age or different constructive systems.

\section{Case study}

\subsection{Building Characterization}

The building under study, Casa do Infante, is located in the historic centre of Oporto, in Portugal, at the riverside zone. The main facade is oriented towards a street with a sharp slope [24] as can be observed in the west elevation in Figure 1. The Oporto town council is the owner of the building. Is composed by 11 blocks, as shown in Figure 2, built in different periods, being the eldest one built between the XIV and the XVII century. According to each block localisation, the number of stories varies from 2 to 8 . All over the years, several interventions in the buildings were conducted (Figure 3).

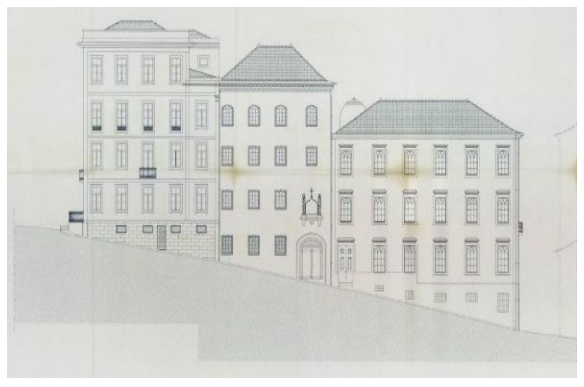

Fig. 1. West elevation

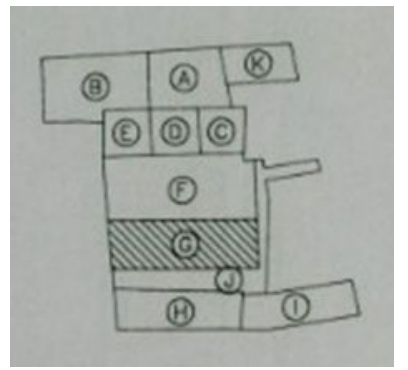

Fig. 2. Blocks organisation 


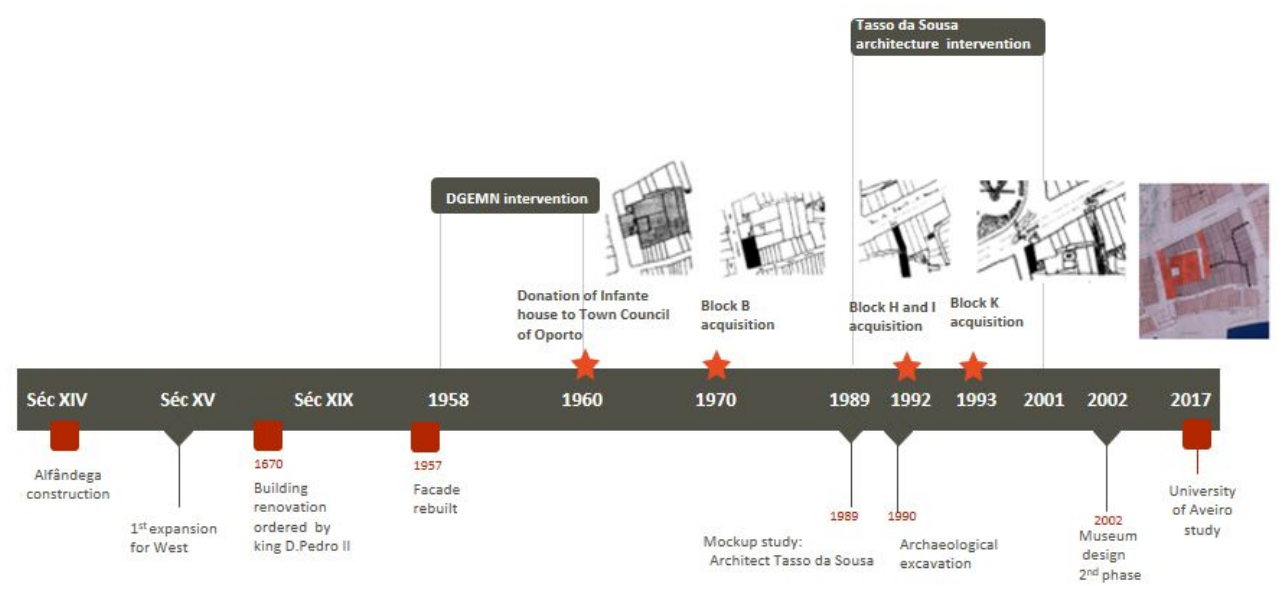

Fig. 3. Timeline of acquisitions and interventions in Casa do Infante

In addition, the use of the building has been changed along the centuries: it was used beyond housing (in the top storeys), to costumes official functions, administration functions and politician functions, however, nowadays, it is functioning as a Museum and Historical Archive of the Oporto city. The different blocks that compose the building have different constructive systems according to the construction period. Buildings are composed of granite masonry, composed of structural walls of 50 to $80 \mathrm{~cm}$ of thickness, with plastering and painting coat or exposed granite stone. The different blocks have different structural construction systems. There are floors composed of timber structure, precast concrete joist and ceramic counter and a mixed structure composed by a steel framework with permanent formwork and concrete slabs. The roof structure also differs according to the blocks, and are composed by armed brick trusses, wooden trusses and concrete slabs.

On the interior side, the walls have different coatings: exposed granite stone or wall with plaster painting coat and/or ceramic tiles. The floors are coated with timber, ceramic porcelain tiles in the bathrooms, marble, wooden parquet, vinyl floor, and garnished granite. The glazing areas are composed of painted wooden frames with a simple glass of 3 $\mathrm{mm}$ and $4 \mathrm{~mm}$ thickness with guillotine open system and cremone lock type. In some blocks, there are interior wooden shutters and in others interior blackouts. The window lintels, shoulder pads and sills are usually in granite on the interior and in some cases in wooden. The roofs are composed of 2, 3 and 4 pitches, coated with ceramic tiles of different types: lusa type, canudo type and marselha type. In the central volume, the roof is in zinc plate coating.

\subsection{Inspection survey and reports}

The identification of anomalies was possible throughout visual inspections and in-situ tests. The inspections done were recorded at inspection support sheets and for each anomaly was done a summary, which contains the causes, recommendations for its correction, as well as, the visual recording of the anomaly. Beyond this, all the constructive and materials characteristics with photographic and technical details were registered. In Table 1 and 2 it is summarised the anomalies recorded and it is possible to verify that the more serious anomalies are in the roof areas. These elements are, also, the main cause of the infiltrations verified in walls and floors. Table 1 summarizes the structural and envelope anomalies and Table 2 (for two of the blocks) depicts the interior anomalies identified. 
Table 1. Summary of the envelope and structural anomalies

\begin{tabular}{|c|c|}
\hline Roofs & Glazing areas \\
\hline $\begin{array}{l}\text { Deformation of ridge and north pitches of the roof. } \\
\text { Degradation of the wooden structure. } \\
\text { The general bad condition of the roof. } \\
\text { Inexistence of slatted to support tiles. } \\
\text { Incorrect placement of thermal insulation. } \\
\text { Degradation of ceramic tiles and development of mosses and } \\
\text { verdigris. } \\
\text { Defective placement of the first tile near to gutter. } \\
\text { Displacement of tiles/ bad position of tiles/ wrong fitted of } \\
\text { tiles. } \\
\text { Dirt gutters, drains and ruffs. } \\
\text { Bad connection between roof and ruffs. } \\
\text { Degradation of mortars and coating of verges. }\end{array}$ & $\begin{array}{l}\text { Regarding glazing areas, it was } \\
\text { usually recorded degradation of } \\
\text { the windows framework, sills and } \\
\text { the low thermal performance } \\
\text { contributing to a decrease of the } \\
\text { thermal comfort of the building. } \\
\text { The windows and doors } \\
\text { framework presents cracks and } \\
\text { lack of bitumen around the } \\
\text { glasses. }\end{array}$ \\
\hline Facades & Structural wooden beams \\
\hline $\begin{array}{l}\text { Run-off water ; Poor adhesion of the mortar; Cracks; } \\
\text { Humidity; Painting detachment; Biological colonization }\end{array}$ & $\begin{array}{l}\text { In blocks B and } K \text {, it was verified } \\
\text { the need of reinforcement and } \\
\text { replacement of some of the } \\
\text { wooden beams. }\end{array}$ \\
\hline
\end{tabular}

Table 2. Summary of indoor recorded anomalies by block

\begin{tabular}{|c|c|}
\hline Block A & Block B \\
\hline $\begin{array}{l}\text { Cracking in the partition wall between block A } \\
\text { and K. } \\
\text { Vertical cracking in the connection between the } \\
\text { facade wall and a partition wall, adjacent to this } \\
\text { damage is the timber floor. } \\
\text { Slight vertical and short length cracking at the } \\
\text { top of a partition wall with west orientation on } \\
\text { floor } 2 \text {. } \\
\text { Mapped fissures on the top of the wall of the } \\
\text { toilet. } \\
\text { Moisture (infiltration) at the base of the wall, in } \\
\text { the semi-buried zone. } \\
\text { Degradation of the stone on the wall, which has } \\
\text { adjacent cracking, and blistering of flooring. } \\
\text { Damage areas of walls and ceilings in the } \\
\text { surrounding of air conditioning devices. }\end{array}$ & $\begin{array}{l}\text { Vertical cracking with some expression, } \\
\text { associated to cracking of stones in a more } \\
\text { dispersed area. Cracking in walls mainly on the } \\
\text { north and south facades, punctually in west and } \\
\text { east. The existence of irregular stone masonry } \\
\text { walls with little joint reclosing. } \\
\text { Presence of areas with dampness and } \\
\text { consequent damage to the covering in half- } \\
\text { buried areas, in partition wall with block E at } \\
\text { the base, next to glazing areas and at the top of } \\
\text { the walls. Degradation of the stone - the } \\
\text { existence of spots and some areas with } \\
\text { dampness and efflorescence. Painting blister in } \\
\text { punctual areas, where the partition wall with } \\
\text { block K meets the west faced. } \\
\text { Some degradation of wood beams with the } \\
\text { presence of xylophages agents. }\end{array}$ \\
\hline
\end{tabular}

\subsection{Results of the methodology application}

In order to establish the refurbishment operations and its priority according to the degradation level of the anomalies, the characterization of the conservation state of each constructive element of the building was done [1]. Follow up the methodology of [22] the process to establish the risk level was adapted to 5 levels. For each one of the five levels of the graduation scale, the evaluation requirements have been specified to be applied to each one of the observed elements. Thus, to make the visual observation easier a degradation scale was defined, where is specified the extension and location of the anomalies for each of the assessed elements and the correspondent degradation level. To the referred case 
study for each of the accessed elements, the degradation scale was applied. The results from the visual assessment were aggregated into a global value for each element and/or anomaly. Accordingly, a method that allows obtaining a global degradation level (DL) for each element and/or anomaly analysed by aggregating the graduations assigned to each area or element of the buildings surveyed was developed. Moreover, departing from these results, the evaluation index (EI) was calculated to each building [22, 23].

Afterwards, a model that allows obtaining a value of the global degradation level was implemented as depicted in Table 3, for roofs and openings that are chosen as an example because they have a higher level of degradation.

Table 3. Global evaluation level of constructive elements

\begin{tabular}{|c|c|c|c|}
\hline $\begin{array}{c}\text { Affected } \\
\text { element }\end{array}$ & \multicolumn{3}{|c|}{ Roof } \\
\hline Level & $\begin{array}{c}\mathrm{N}^{\mathrm{o}} \text { of } \\
\text { times } \\
\text { level } \\
\text { appears }\end{array}$ & $\%$ & Grade \\
\hline 5 & 0 & - & FALSE \\
\hline 4 & 0 & - & FALSE \\
\hline 3 & 0 & - & FALSE \\
\hline 2 & 5 & $63.00 \%$ & DL=2 \\
\hline 1 & 3 & $37.00 \%$ & FALSE \\
\hline
\end{tabular}

\begin{tabular}{|c|c|c|c|}
\hline $\begin{array}{c}\text { Affected } \\
\text { element }\end{array}$ & \multicolumn{3}{|c|}{ Openings } \\
\hline Level & $\begin{array}{c}\mathrm{N}^{\mathrm{o}} \text { of } \\
\text { times } \\
\text { level } \\
\text { appears }\end{array}$ & $\%$ & Grade \\
\hline 5 & 5 & $36.00 \%$ & FALSE \\
\hline 4 & 0 & 0 & FALSE \\
\hline 3 & 1 & $7.00 \%$ & FALSE \\
\hline 2 & 2 & $14.00 \%$ & FALSE \\
\hline 1 & 6 & $43.00 \%$ & DL=1 \\
\hline
\end{tabular}

Aggregating the values through the aggregation conditions [22] the degradation level of the building, named evaluation index (EI), was obtained (EI=3 an average value).

\section{Conclusions}

Tools and proceedings have been developed and adjusted to support field visual inspection. These proceedings constitute useful tools to support technicians and to support the building identification and characterization. The adjustment of the methodology of "state of conservation assessment of residential buildings at controlled costs" was done to be simpler to use in the field. This methodology was applied to a heritage building, Casa do Infante, to show the viability of its application to other buildings different from housing, and the usefulness of this method to define the conservation state of a building, in order to propose adequate refurbishment solutions. Through this building assessment, it is possible to plan maintenance activities and propose corrective and preventive maintenance tasks.

According to the building assessment, the roofs are generally in poor conditions (level of degradation 2) and a great number of openings are in unacceptable conditions (level of degradation 1). From these results, it is possible to conclude that these elements have an immediate need of refurbishment. This methodology reveals important and useful information about the priority of interventions and which of them are more critical, permitting to prioritize the interventions.

In addition, a specialised project design for roof refurbishment has to be developed. Besides that, this building should have maintenance plans, for every element, in order to plan the maintenance actions that should be implemented over the building life cycle. 


\section{References}

1. M.F. Rodrigues, $\mathrm{PhD}$ thesis, UA (2008)

2. INE and LNEC (2013)

3. INE ( 2003)

4. MAEC, LNEC (2006)

5. A. Vilhena, PhD thesis, IST (2011).

6. ODPM, Housing Health and Safety Rating System Enforcement guidance (ODPM Publications, 2006)

7. CSHP, Grille de visite des immeubles susceptibles d'être déclarés insalubres (Conseil Supérieur d'Hygiène Publique de France, 2003)

8. NEN 2767-1, Evaluation of building conservation state and its installation components - Part 1: Methodology (2006)

9. NEN 2767-2, Evaluation of building conservation state and its installation components - Part 2: list of anomalies (2008).

10. NEN 2767-3, Evaluation of building conservation state and its installation components - Part 3: Aggregation of the evaluation results to calculate technique index (2009).

11. C.A Balaras, Eng. and Build., 31, 2 (2000).

12. C.A Balaras, En. and Build., 34, 2 (2002).

13. D. Caccavelli, H. Gugerlib, En. and Build., 34, 2, 113-119 (2002)

14. Collectif d'auteurs, Guide Socotec de la maintenance et de la réhabilitation - Tome 1 et Tome 2 (Groupe Moniteur, 2001).

15. B. Marteinsson, B. Jónsson, B., 8th Int. Conf. on Durability of Building Material and Components, 1634 - 1654 (1999)

16. Z. Lounis, D. Vanier, M. Lacasse, B. Kyle, First Int. Conf. on New Inf. Technologies for Decision Making in Construction, 425 - 436 (1998)

17. P.L. Gaspar, J. Brito, 10th Int. Conf. on Durability of Building Material and Components, Paper TT8 - 68 (2005)

18. E. Ai L. Teo, 10th Int. Conf. on Durability of Building Material and Components, Paper TT4 - 152 (2005)

19. P.L.Gaspar et al., PATORREB 2006, 541-550 (2006)

20. I.M.Shohet, M. Paciuk, Const. Manag. and Economics, 24, 2, 131-148 (2006)

21. F. Rodrigues, J. Teixeira, J. Cardoso, J. Anjos, Civil Eng. and Environ. Systems, 30, 1, 26-39 (2012)

22. F. Rodrigues, R. Matos, M. Di Prizio, A. Costa, Const. and Build. Mat., 172, 781-786 (2018)

23. F. Rodrigues, J. Teixeira, J. Cardoso, Const.and Build. Mat. 25, 741-2750 (2011)

24. I. Sereno, I., P. Dordio, Available on http://www.monumentos.pt/site/APP PagesUser/SIPA.aspx?id=545 (1995) 